\title{
Biology of the Mountain Crayfish Euastacus sulcatus Riek, 1951 (Crustacea: Parastacidae), in NeW South Wales, Australia
}

\section{Jason Coughran}

\begin{abstract}
The biology and distribution of the threatened Mountain Crayfish Euastacus sulcatus, was examined through widespread sampling and a long-term mark and recapture program in New South Wales. Crayfish surveys were undertaken at 245 regional sites between 2001 and 2005, and the species was recorded at 27 sites in the Clarence, Richmond and Tweed River drainages of New South Wales, including the only three historic sites of record in the state, Brindle Creek, Mount Warning and Richmond Range. The species was restricted to highland, forested sites (220-890 m above sea level), primarily in national park and state forest reserves. Adult crayfish disappear from the observable population during the cooler months, re-emerging in October when the reproductive season commences. Females mature at approximately $50 \mathrm{~mm} \mathrm{OCL}$, and all mature females engage in breeding during a mass spawning season in spring, carrying 45-600 eggs. Eggs take six to seven weeks to develop, and the hatched juveniles remain within the clutch for a further 2.5 weeks. This reproductive cycle is relatively short, and represents a more protracted and later breeding season than has been inferred for the species in Queensland. A combination of infrequent moulting and small moult increments indicated an exceptionally slow growth rate; large animals could feasibly be $40-50$ years old. Implications for the conservation and management of $E$. sulcatus are discussed.
\end{abstract}

Keywords: Conservation, Euastacus, IUCN, growth, moulting, reproduction, spiny crayfish, subtropical rainforest, threatened species.

Abbreviations: AbGR - absolute growth rate; AbW - abdominal width; NP - National Park; NSW - New South Wales; OCL - orbital carapace length (see Morgan 1997); PCMI - percent moult increment; PropL - propodal length; SF - State Forest

DOI: http://dx.doi.org/10.11609/JoTT.o3647.4840-53 | ZooBank: urn:Isid:zoobank.org:pub:A250C1DA-124E-4742-B1D8-697DABEE542D

Manuscript details: Ms \# 03647 | Received 01 June 2013 | Final received 02 October 2013 | Finally accepted 05 October 2013

Citation: Coughran, J. (2013). Biology of the Mountain Crayfish Euastacus sulcatus Riek, 1951 (Crustacea: Parastacidae), in New South Wales, Australia. Journal of Threatened Taxa 5(14): 4840-4853; http://dx.doi.org/10.11609/JoTT.03647.4840-53

Copyright: (C Coughran 2013. Creative Commons Attribution 3.0 Unported License. JoTT allows unrestricted use of this article in any medium, reproduction and distribution by providing adequate credit to the authors and the source of publication.

Funding: Funding was provided by Southern Cross University, the Australian Geographic Society, and jagabar Environmental.

Competing Interest: Author declare no competing interests.

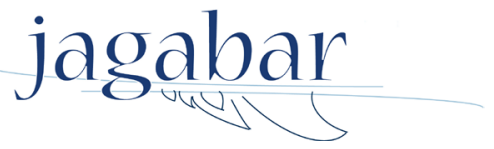

Author Details: Jason Coughran completed a PhD in Biology at Southern Cross University in 2006, and his research interests are the biology, ecology, taxonomy and conservation of aquatic fauna, with a focus on inland systems. He is currently engaged in these fields through a private research and consulting entity, jagabar Environmental.

Acknowledgements: This work was undertaken during my postgraduate research at Southern Cross University, and I thank my supervisor Don Gartside and the technical staff who assisted me: Craig Taylor, Max Egan, Maxine Dawes, Peter Bligh-Jones and Roz Hagan. Research funds were provided by Southern Cross University and the Australian Geographic Society. Amy Coughran, Andy Moore, Ben Black, David Newell, Paul Collins, Shawn Leckie and Stephen Waddington assisted with field work for this species, and the National Parks and Wildlife Service, NSW Fisheries and State Forests of NSW departments provided scientific collection permission. I thank Jagabar Environmental for providing me with time to prepare the manuscript, and two anonymous reviewers for their constructive comments. 


\section{INTRODUCTION}

Edgar Riek (1951) formally described the Mountain Crayfish, Euastacus sulcatus, from over one hundred specimens collected from Tamborine Mountain and Lamington National Park (NP) in southeastern Queensland, Australia. In the same paper, Riek also described E. cunninghami from Cunningham's Gap. These taxa were distinguished largely on the basis that E. cunninghami was more setose and had reduced abdominal spination. However, it subsequently became apparent that these two species were conspecific, and the latter was synonymised with $E$. sulcatus by Morgan (1988).

The collections by Morgan (1988) also provided a more complete understanding of the distribution for $E$. sulcatus, extending in an arc from Tambourine Mountain to the Lamington Plateau, westwards along the McPherson Range bordering New South Wales (NSW), and north again to the Mistake Mountains. He recorded the species from only two NSW sites, at Brindle Creek and Mount Warning (Morgan 1988). The species was subsequently recorded further west in NSW, on the Richmond Range (Leckie 1999; Coughran 2000), prompting a comprehensive research program on its distribution, taxonomy, biology and ecology (Coughran 2006a).

Euastacus sulcatus is a large, spiny crayfish species, reaching up to $340 \mathrm{~mm}$ in overall length, and $425 \mathrm{~g}$ in weight (Furse \& Wild 2004). The species differs from most other large, spiny species of Euastacus, including $E$. suttoni and $E$. valentulus in the immediate region, in that it lacks thoracic spines. It is also regionally unique because it exhibits marked base colour variation: for example, specimens from the Lamington Plateau and Springbrook in Queensland are blue, while specimens from Brindle Creek and the Richmond Range in NSW are typically red (Morgan 1988; Coughran 2000, $2006 a, b)$. In addition to its striking colouration, large size and impressive spination, E. sulcatus has become an iconic species for park visitors, due to its tendency to periodically wander around on forest floors (Riek 1951; Morgan 1991; Furse \& Wild 2002b; Furse et al. 2004).

Despite the above, several knowledge gaps remain for this species, which has recently been formally recognised as Endangered on the IUCN Red List of Threatened Species (Furse \& Coughran 2010). Filling these knowledge gaps is of fundamental importance to ensuring the conservation of this species. For example, although the ecology and population characteristics of $E$. sulcatus have been relatively well studied in
Queensland (Furse \& Wild 2002a,b, 2004; Furse et al. 2004, 2006), its NSW distribution is unclear. Further, many biological aspects remain undocumented including: (i) the incidence of wounds and disease; (ii) reproductive biology details; and (iii) wild moulting and growth increments. In this paper, I present the findings of a detailed biological research program encompassing both broad field surveys in NSW, and a two-year mark and recapture program examining the biology of $E$. sulcatus.

\section{METHODS}

Field surveys were undertaken at 245 sites across northeastern NSW between 2001 and 2005, with the aim of thoroughly describing the taxonomy, distribution, habitat and ecology of all regional crayfish species (Coughran 2006a). Sampling was undertaken via NSW Scientific Collection permits, and the NSW National Parks and Wildlife Service's (2001) Frog Hygiene Protocol was followed throughout the study. Crayfish were collected by hand or hand net, with baited string lines or traps (with meat baits), or by lifting rocks and other debris and probing burrows by hand. Both diurnal and nocturnal surveys were undertaken, and observations were made of crayfish activity, conspecific interactions and the presence of wounds and disease. Habitat characteristics and basic water quality parameters $(\mathrm{pH}$, conductivity, dissolved oxygen and temperature) were recorded throughout the study.

\section{Population Study: Brindle Creek (Images 1 \& 2)}

In addition to data collected from surveys across the species' NSW range, a long-term monitoring site was established at Brindle Creek, in the World Heritage listed Border Ranges NP (Fig. 1). The site comprised typical Brindle Creek habitat, the predominant locality of three historic sites of record for the species in NSW, and sufficiently far away (and upstream) from the popular recreational part of the park to avoid visitor impacts. The site encompassed a stream length of approximately $500 \mathrm{~m}$.

The creek at this site was relatively large, reaching widths of 5-10 m, and with pools often 1-2 m deep. There was a permanent flow in the creek, and all sections retained some surface water throughout the sampling period. The substratum was generally fine, but also incorporated a coarser component of gravelly sand in places. There was moderate to dense cobble and boulder cover in most of the larger pools, in which rocks 


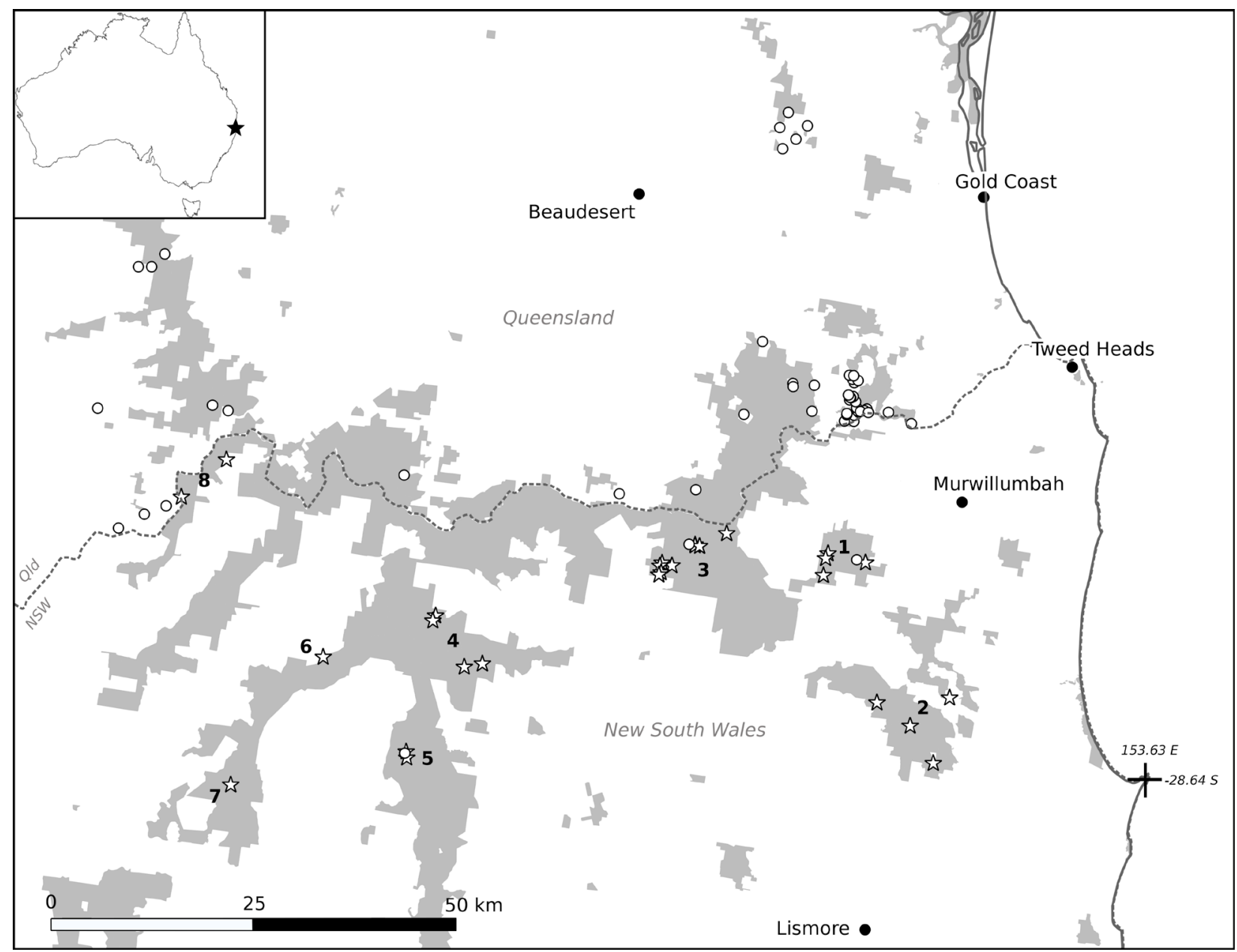

Figure 1. The NSW distribution of the Mountain Crayfish, Euastacus sulcatus, was greatly extended during the study (new sites indicated with stars), and the species was also recorded at all previously known sites (circles). Distinct NSW populations are numbered, as follows:

1 - Mount Warning; 2 - Nightcap; 3 - Border Ranges (including Brindle Creek); 4 - Toonumbar; 5 - Richmond Range; 6 - Yabbra (north); 7 - Yabbra (south); 8 - Koreelah. Known sites of record from Queensland are represented by circles.

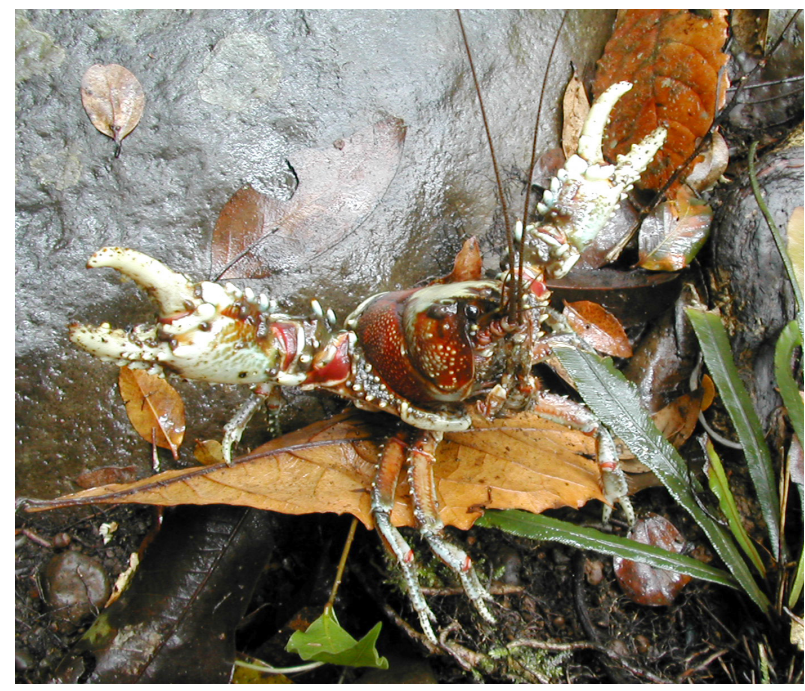

Image 1. Mountain Crayfish Euastacus sulcatus in natural habitat (23.iv.2003, () Jason Coughran, Brindle Creek).

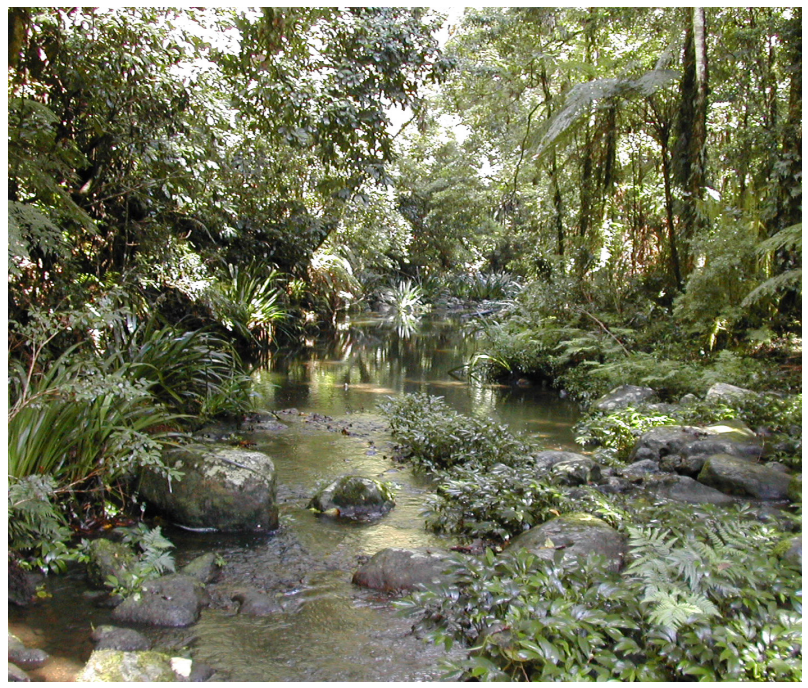

Image 2. Natural habitat of Euastacus sulcatus (03.ii.2002, ㄷ Jason Coughran, Brindle Creek). 
were sparsely distributed, often in small aggregations. The banks were generally gentle to moderate in slope, although in some stretches the banks were steep, and occasionally vertical. The site received a moderate amount of sunlight, but submerged aquatic plants were absent. Exposed rocks in the stream bed, however, were often covered with semi-aquatic plants such as Rainforest Spinach Elatostema reticulatum. The surrounding forest was subtropical rainforest.

\section{Marking}

The Brindle Creek crayfish population was sampled monthly from August 2001 to July 2003. Animals were marked with a unique identifier using the tailfan clipping code of Coughran (2011a). Some animals with damaged tailfans were not clippable and were excluded from marking. A small number of aggressively protective berried females were not marked, to avoid disturbing the clutch. Generally, however, berried females were marked. All crayfish marked at the long-term monitoring site were returned to the water at the point of capture.

Crayfish were measured with vernier calipers to the nearest $0.1 \mathrm{~mm}$ for $\mathrm{OCL}$ and abdominal width (Morgan 1997). Both chelae were also measured for propodal length, width and depth. Chelae were considered normal (i.e., non-regenerate) when they differed by $<1 \mathrm{~mm}$ propodal length from their counterpart; otherwise they were noted as slightly regenerate (1-3 $\mathrm{mm}$ smaller) or distinctly regenerate $(>3 \mathrm{~mm}$ smaller than their counterpart).

\section{Density}

Crayfish density (per linear m of stream) at the Brindle Creek site was estimated from the mark-recapture data, using three multiple census equations:

- the original and adjusted Schnabel methods (Schnabel 1938; Chapman 1952); and

- the Schumaker method (Ricker 1975).

Animals that were captured more than one time during a monthly session were considered once only in the population estimates. Some animals were excluded from the analyses, including specimens $<15 \mathrm{~mm} \mathrm{OCL}$, and specimens that were badly injured during collection.

\section{Growth and Moulting}

Crayfish were designated to have an 'exoskeleton condition', as described by Coughran (2011a), and a subsequent change in exoskeleton condition was used to verify moult events for recaptured individuals. Where possible, pereiopod regeneration was also used to verify moult events. Two methods of growth rate estimation were applied to the mark-recapture data:

- Percent Moult Increment (PCMI) was combined with an estimate of moult frequency to estimate growth (Hamr \& Richardson 1994; Hamr 1997; Borsboom 1998); and

- Absolute Growth Rate (AbGR), taken as the change in OCL since last capture divided by the number of months since last capture (Lake \& Sokol 1986).

\section{Maturity}

The gonopores of female crayfish were examined for secondary sexual characteristics, including: development of setae around the female gonopores; the level of inflation of the gonopores in comparison to the surrounding coxal surface; and whether gonopores were still calcified or membranous. These data were used to assign maturity stages, similar to those established for Euastacus bispinosus by Honan \& Mitchell (1995c), as follows:

- Immature: Gonopores small, level with surrounding coxal surface, and calcified;

- Adolescent: Rim of gonopore incised, a few setae may be present on the coxal surface surrounding the gonopore, often the gonopore is slightly darker than the surrounding coxal surface, sometimes decalcified but not raised or membranous; and

- Mature: Gonopore decalcified, fleshy looking and raised like a blister above the surrounding coxal surface, often fringed by dense setae.

Relative abdominal width (i.e., $\mathrm{AbW} / \mathrm{OCL}$ ) and chela size (i.e., PropL/OCL) have also been used as secondary indicators of sexual maturity (Honan \& Mitchell 1995c; Hamr 1997). It has been noted in other species that males develop proportionally larger chelae, and females develop proportionally larger abdomens, as they mature. Comparisons of these measurements for male and female $E$. sulcatus were analysed and tested for significance with the normal probability density function and Student's $t$ test.

\section{Egg Size, Fecundity and Spawning}

For all females carrying eggs or juveniles (i.e., "berried"), fecundity was estimated in the field, and up to 20 eggs were retained from selected crayfish for subsequent laboratory measurement (total sample: 163 eggs taken from 24 females). The retained eggs were examined using a dissecting microscope, photographed and measured. Mean egg sizes (egg width, measured across the shortest axis; and egg length, measured 
across the longest axis) were calculated, and ratios of egg width/OCL and egg length/OCL were determined.

To complement field observations of reproductive activity, three ovigerous females were retained from the wild and maintained in laboratory aquaria. The laboratory was permanently air-conditioned to $22^{\circ} \mathrm{C}$, and water temperatures in the aquaria generally remained within $1-2{ }^{\circ} \mathrm{C}$ of this throughout the study. Female crayfish were provided with a leaf litter and sand substrate with rock, decaying wood and pipe shelters, and supplemental food in the form of algae pellets and flaked food. Two or three eggs, or juveniles, were removed from the reproductive females twice weekly, and examined under a dissecting microscope and photographed. The entire clutch of eggs, or juveniles, was also photographed periodically during the developmental period.

Independent juveniles were grown in matured 80 litre aquaria, with a substrate of sand, gravel and leaf litter from their wild habitat. Long maturation had enabled an algal growth and invertebrate fauna to develop in these aquaria, and the juvenile crayfish were provided with minimal supplemental food.

\section{RESULTS}

\section{Distribution}

Euastacus sulcatus was recorded at 27 sites, including the three NSW historical sites. The species distribution was substantially extended south along the Tweed Range, southeast along the Nightcap Range and on Mt Warning, and westward along the McPherson Range to Koreelah NP (Fig. 1). The species is now known to occur in the Tweed, Richmond and Clarence River drainages of northeastern NSW, and is relatively widespread in this state.

Although the species was morphologically similar across its range, and generally consistent with the current taxonomic description (Morgan 1988), colouration varied markedly between the different populations across its distribution. Most western populations (e.g., Border Ranges, Richmond Range, Koreelah) displayed a red base colour, as is also common in western Queensland (Coughran, unpub. data). In the Nightcap Range, crayfish had a blue base colour, previously thought restricted to south-eastern Queensland (Furse \& Wild 2002a). Large animals from all populations in the species' range had the prominent pale patches, or "shields", on the abdomen, carapace and chelae that is characteristic of the species. These shields were usually a cream colour, however crayfish from eastern Mount Warning had turquoise shields over a red base colour, and those from Yabbra had tan shields over a very dark brown (almost black) base colour (Images 3 \& 4). The extent of development of the shields varied considerably, and in some cases dominated the colour of the animal. Photographs of these various colour forms of E. sulcatus in NSW have been provided elsewhere (Coughran 2006b).

\section{General Ecology}

The species occurred in rainforest habitats, or wet sclerophyll forest with gallery rainforest along the stream margins, in national parks or relatively undisturbed areas of state forests with similar habitat. One exception was a private site where the species was recorded in a minor gully lacking surface water, within a small (i.e., $20 \mathrm{~m} x$ $20 \mathrm{~m}$ ) remnant patch of gallery rainforest. Otherwise,

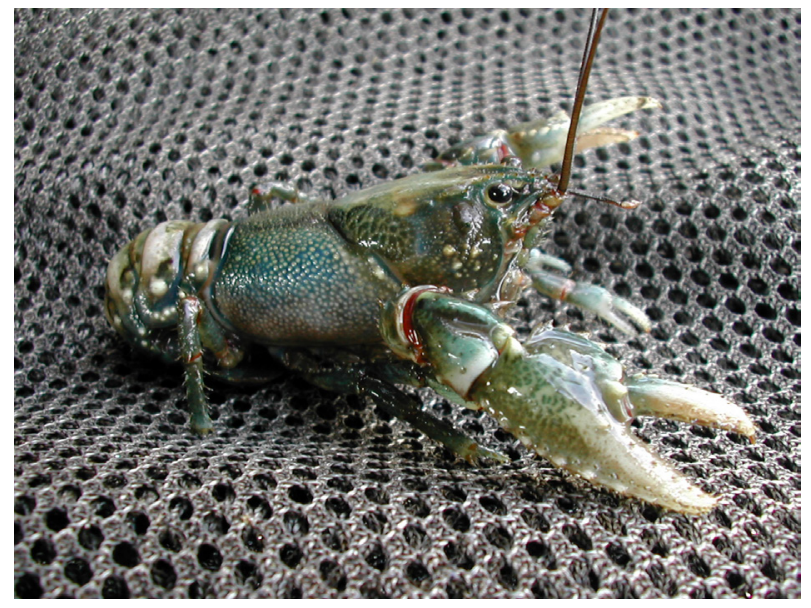

Image 3. Euastacus sulcatus blue and cream form Brummies Creek (06.ix.2002, @ Jason Coughran)

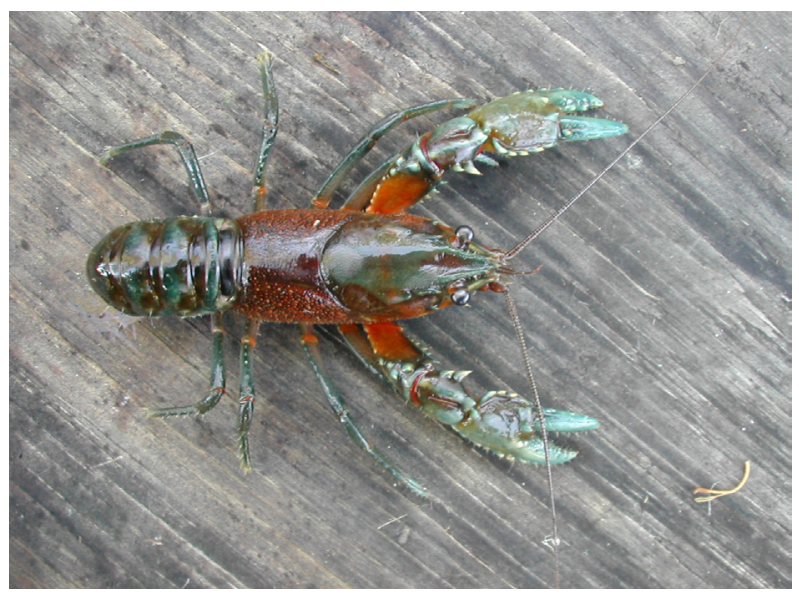

Image 4. Euastacus sulcatus red and turquoise form Korrumbyn Creek eastern Mt Warning (13.iv.2002 @ Jason Coughran) 
the species was recorded from publicly managed areas, including Border Ranges, Koreelah, Mount Warning, Nightcap, Richmond Range, Toonumbar and Yabbra NPs, and Whian Whian, Wollumbin and Yabbra SFs. The species was found at altitudes above $220 \mathrm{~m}$, extending upwards to $890 \mathrm{~m}$.

The species inhabited a wide variety of aquatic and semi-aquatic habitats, from moist gullies with no surface water to large, flowing streams. The conductivity was relatively low $(<350 \mu \mathrm{S} / \mathrm{cm})$, the $\mathrm{pH}$ ranged from 6.08 8.04 , and the water temperature ranged from $7-24{ }^{\circ} \mathrm{C}$. The minimum dissolved oxygen concentration recorded was $6.08 \mathrm{mg} / \mathrm{L}$. The substrate varied from fine silt to gravel. Where cover was found in the form of rocks and woody and leafy debris, the species commonly excavated burrows into the stream bed. Burrows were also common in stream banks and in the adjacent forest floor. In large streams, wide burrows and pits were excavated in banks and beneath boulders and logs, from which numerous animals of varying sizes were often lured out. It therefore appeared that the species had both communal and solitary habits. Burrows in the stream bed not associated with cover were less common.

\section{Activity}

Except for small juveniles, crayfish were absent from the stream during the cooler months, from April to October. When the animals returned in the warmer months, the mature females were berried.

Euastacus sulcatus were mostly diurnal, and during the months when animals were more active they were commonly encountered. Crayfish were commonly observed transiting the forest, particularly during wet weather. During high stream flow periods some animals were engaged in harvesting vegetation (e.g., moss or riparian plants), or carrying washed out vegetation or small pieces of tree-falls back to their burrows. Throughout the active months, E. sulcatus were readily trapped or lured out of burrows; if direct bait access was impossible animals often partially consumed any trapassociated materials (e.g., hessian, stockings, plastic, netting, ropes or floats).

\section{Population Study: Brindle Creek}

In total, 301 animals from the Brindle Creek site (including recaptured animals), and a further 100 crayfish from other sites in the broad distribution surveys, were measured and examined. A maximum size of $90.8 \mathrm{~mm}$ OCL was recorded for $E$. sulcatus at the Brindle Creek site, and $99.5 \mathrm{~mm} \mathrm{OCL}$ at other sites. This was considerably larger than the maximum $\mathrm{OCL}$ (i.e.,
$81.1 \mathrm{~mm}$ ) recorded by Morgan (1988). The smallest trapped animal was $20.8 \mathrm{~mm} \mathrm{OCL}$, and the smallest caught by hand was $7.5 \mathrm{~mm}$ OCL.

One-hundred-and-ninety-nine animals were marked at the Brindle Creek site. Thirty-one of these (15.6\%) were recaptured at least once, with seven recaptured twice or more (up to a maximum of nine recaptures). The mean monthly recapture rate was $13 \%$. The estimated crayfish density at the site was approximately 1.5 crayfish per linear metre (Table 1 ).

\section{Wounds and Disease}

Wounds were recorded on 98 crayfish (32.6\%) from the Brindle Creek site, and 37 crayfish (37.0\%) from other sites. In addition to missing or damaged pereiopods, wounds were most commonly recorded in the cephalothorax, rostrum and chelae. Seventeen animals had burn spot disease on the carapace or chelae. One adult female $(69.3 \mathrm{~mm} \mathrm{OCL})$ had a small carapace wound, and when recaptured one month later, its carapace had mostly deteriorated on one side, leaving the gills completely exposed. The crayfish appeared behaviorally unaffected by this substantial wound, and it was observed actively hunting in the stream before being recaptured.

Ten animals $(<2.5 \%)$ sacrificed a chela during handling, and these were excluded from the following analyses. Only $52.7 \%$ of the animals from Brindle Creek bore two normal chelae. Approximately $5.7 \%$ of animals were either missing a chela or bore only soft chela buds, $18.2 \%$ had a distinctly regenerate chela and $23.3 \%$ had a slightly regenerate chela.

\section{Moulting}

Animals in the process of moulting were commonly captured from within burrows under rocks. Several animals were also observed moulting in shallow waters of the open stream, usually on a rock top. Because most crayfish were absent from the water body during the winter months, the records of moulting were considered unreliable for defining a growing season.

Table 1. Estimates of population density for Euastacus sulcatus from the long-term biological monitoring site at Brindle Creek (site length $500 \mathrm{~m})$.

\begin{tabular}{|l|c|c|c|}
\hline Estimation Method & $\mathbf{N}$ & $\mathbf{9 5 \%} \mathrm{CL}$ & $\begin{array}{c}\text { crayfish per } \\
\text { linear metre }\end{array}$ \\
\hline Schnabel & 784.97 & $561.87-1135.7$ & 1.57 \\
\hline Schnabel (modified) & 762.54 & $548.03-1098.31$ & 1.53 \\
\hline Schumaker & 736.66 & $550.08-1114.78$ & 1.47 \\
\hline
\end{tabular}


Table 2. Growth and moulting records for recaptured Euastacus sulcatus, from Brindle Ck, and determination of the PCMI (\%) and AbGR ( $\mathrm{mm} /$ month) for OCL. C»R, earliest and latest months of capture and recapture for each growth interval; $t_{m}$, time in months between capture records; Moults*, estimated number of moults between records; Initial, OCL prior to moulting (mm); Final, OCL after moulting (mm); MI, moult increment $(\mathrm{mm})$. Two entries marked * are for the same individual, which moulted twice during the study, and was recaptured and measured each time.

\begin{tabular}{|c|c|c|c|c|c|c|c|}
\hline$C » R$ & $t_{\mathrm{m}}$ & Moults* & Initial & Final & MI & PCMI & AbGR \\
\hline \multicolumn{8}{|l|}{ Females } \\
\hline Feb-Oct & 8 & 1 & 53.1 & 57.4 & 4.3 & 8.1 & 0.5 \\
\hline Nov-Oct & 11 & 1 & 70.9 & 73.4 & 2.5 & 3.5 & 0.2 \\
\hline Nov-Oct & 11 & 1 & 67.6 & 69.2 & 1.6 & 2.4 & 0.1 \\
\hline Nov-Feb & 15 & 1 & 57.0 & 60.8 & 3.8 & 6.7 & 0.3 \\
\hline Mean (Female) & & & & & & 5.2 & 0.3 \\
\hline \multicolumn{8}{|l|}{ Males } \\
\hline Nov-Feb & 3 & 1 & 52.8 & 56.8 & 4.0 & 7.6 & 1.3 \\
\hline Nov-May* & 6 & 1 & 54.4 & 58.5 & 4.1 & 7.5 & 0.7 \\
\hline Nov-May & 6 & 1 & 60.0 & 64.6 & 4.6 & 7.7 & 0.8 \\
\hline Aug-Feb & 6 & 1 & 75.6 & 77.9 & 2.3 & 3.0 & 0.4 \\
\hline Aug-Mar & 7 & 1 & 46.6 & 51.0 & 4.4 & 9.4 & 0.6 \\
\hline Nov-Nov* & 12 & 1 & 49.1 & 54.4 & 5.3 & 10.8 & 0.4 \\
\hline May-Jun & 13 & 1 & 76.1 & 78.2 & 2.1 & 2.8 & 0.2 \\
\hline Jan-Feb & 13 & 1 & 61.6 & 65.0 & 3.4 & 5.5 & 0.3 \\
\hline Mar-May & 14 & 1 & 72.0 & 73.6 & 1.6 & 2.2 & 0.1 \\
\hline Jan-Oct & 21 & 1 & 81.5 & 83.6 & 2.1 & 2.6 & 0.1 \\
\hline Mean (Male) & & & & & & 5.9 & 0.5 \\
\hline Mean (Overall) & & & & & & 5.7 & 0.4 \\
\hline
\end{tabular}

Only 13 of the 31 recaptured Euastacus sulcatus moulted between captures, although one of these animals moulted twice during the study (and was captured and measured at each moult). Thus, there were 14 growth records for $E$. sulcatus (Table 2). Most of these recaptures were over long periods, providing some useful insights into the growth of this species. The moult increment in E. sulcatus appears to be correlated with size. Animals $<50 \mathrm{~mm}$ OCL had PCMls (for OCL) of around $10 \%$, animals from $50-60 \mathrm{~mm}$ OCL had PCMIs of $6.7-8.1 \%$, and animals over $60 \mathrm{~mm}$ OCL had PCMIs of $2.2-5.5 \%$. This trend of decreasing growth with increasing size can be seen in one male animal for which two years of moulting records are available. In the first year of records, it increased from 49.1-54.4 mm OCL (PCMI 10.8\%), and in the second year it increased a further 4.1-58.5 mm OCL, representing a lower PCMI (7.5\%).

The 13 Euastacus sulcatus animals that had been recaptured over periods of six months or more had AbGRs (for OCL) of less than $1 \mathrm{~mm} /$ month. For the six animals recaptured over periods of 12 months or more, the AbGR ranged between 0.1 and $0.4 \mathrm{~mm} /$ month (Table 2). Eighteen Euastacus sulcatus were recaptured that displayed no growth between captures. The time intervals between captures for these animals ranged up to eight months (generally between 3 to 4 months, but including four records over five months), and extended across all seasons.

\section{Reproductive Biology}

Sexual dimorphism was evident in a proportionally larger propodal length (i.e., larger chelae; student's $t$ test, $\mathrm{p}<0.001$ ) in males, and a broader abdomen (normal probability density function, $\mathrm{p}<0.0001$ ) in females (Table 3). Three specimens were observed with aberrant sexual characteristics. These included one specimen with two male gonopores and one female gonopore, and two specimens with only a single female gonopore (i.e., gonopore present on one side only).

Females generally reached sexual maturity at or above $50 \mathrm{~mm}$ OCL (Fig. 2), although two females were recorded with mature gonopore states at considerably smaller sizes $(23.7 \mathrm{~mm}, 28.8 \mathrm{~mm})$. An aberrant female 


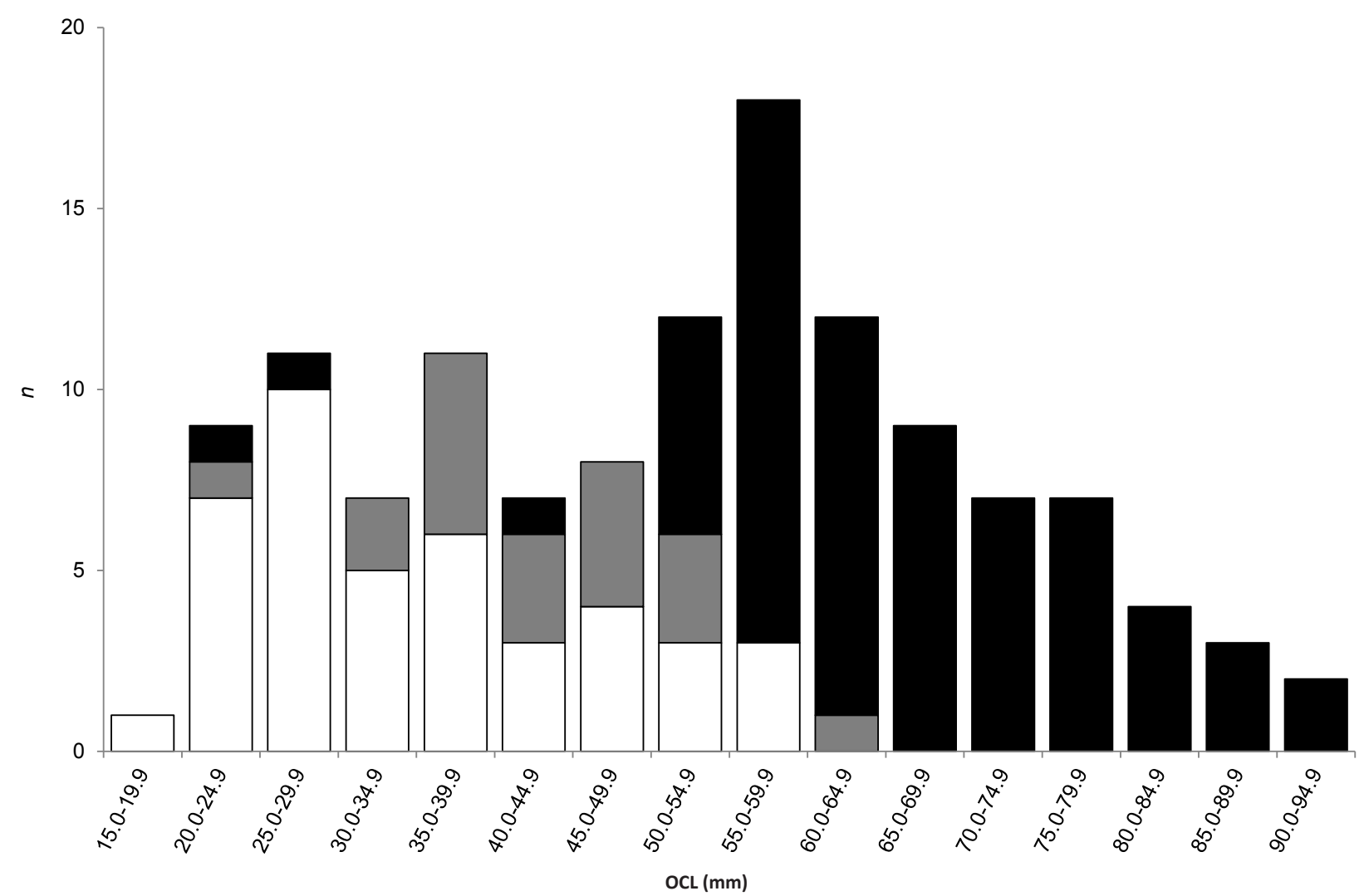

Figure 2. Number of immature (white), adolescent (grey) and mature female (black) Euastacus sulcatus from the long-term monitoring site at Brindle Creek as determined by gonopore state.

Table 3. Sexual dimorphism for $E$. sulcatus animals (>50 mm OCL) from the long-term monitoring site at Brindle Creek: i) relative abdomen width ( $\mathrm{AbW} / \mathrm{OCL}$ ); and ii) relative propodal length (PropL/ $\mathrm{OCL}$ ). $\mathrm{F}=$ female; $\mathrm{M}=$ male; NPDF = normal probability density function.

\begin{tabular}{|l|c|c|c|c|}
\hline & \multicolumn{2}{|c|}{ AbW/OCL } & \multicolumn{2}{c|}{ PropL/OCL } \\
\hline Sex & $\mathbf{F}$ & $\mathbf{M}$ & $\mathbf{F}$ & $\mathbf{M}$ \\
\hline mean ratio & 0.53 & 0.47 & 0.81 & 0.87 \\
\hline$n$ & 76 & 66 & 39 & 24 \\
\hline S.D. & 0.091 & 0.019 & 0.020 & 0.046 \\
\hline S.E. & 0.011 & & 0.01 & \\
\hline test & NPDF & & $\begin{array}{c}\text { Student's } \\
\text { t-test }\end{array}$ \\
\hline$p$ & $<0.0001$ & & $<0.001$ & \\
\hline
\end{tabular}

of $41.5 \mathrm{~mm}$ OCL also had mature gonopores. Ten females $>50 \mathrm{~mm}$ OCL had immature (6) or adolescent (4) gonopore characteristics. All females $>65 \mathrm{~mm}$ OCL were sexually mature. The mean $\mathrm{AbW} / \mathrm{OCL}$ ratio for mature, female $E$. sulcatus was $0.55(n=66)$, and 0.50 for both immature $(n=42)$ and adolescent $(n=19)$ animals.

Forty-eight Euastacus sulcatus females were carrying eggs or juveniles when captured. These females ranged from 51.5-90.4 $\mathrm{mm} \mathrm{OCL}$, and the clutches were estimated to contain between 45-600 eggs. The egg length was approximately $5-8 \%$ of the OCL of the female carrying them; the mean egg length was $4.09 \mathrm{~mm}$, and the mean egg width was $3.19 \mathrm{~mm}$.

The berried females were in variable condition with regard to wounds; two females had at least one chela missing (one had both chelae missing), 25 had a regenerate chela; and two had other missing or regenerate pereiopods. Other wounds recorded on berried females included tailfan damage (2), burn spot (2), and broken or regenerate dactylar or propodal fingers (4). Forty-six of the 48 females $(95.8 \%)$ had very clean exoskeleton states. Thirteen of the 48 females carried brown and/or white temnocephalan flatworms.

The timing of reproductive activity for the 48 berried E. sulcatus females (Fig. 3) clarified this as a late spring-summer brooder, with release of juveniles in early summer. Most females over the minimum size at egg bearing $(51.5 \mathrm{~mm})$ that were captured during this reproductive season were carrying eggs or young. 


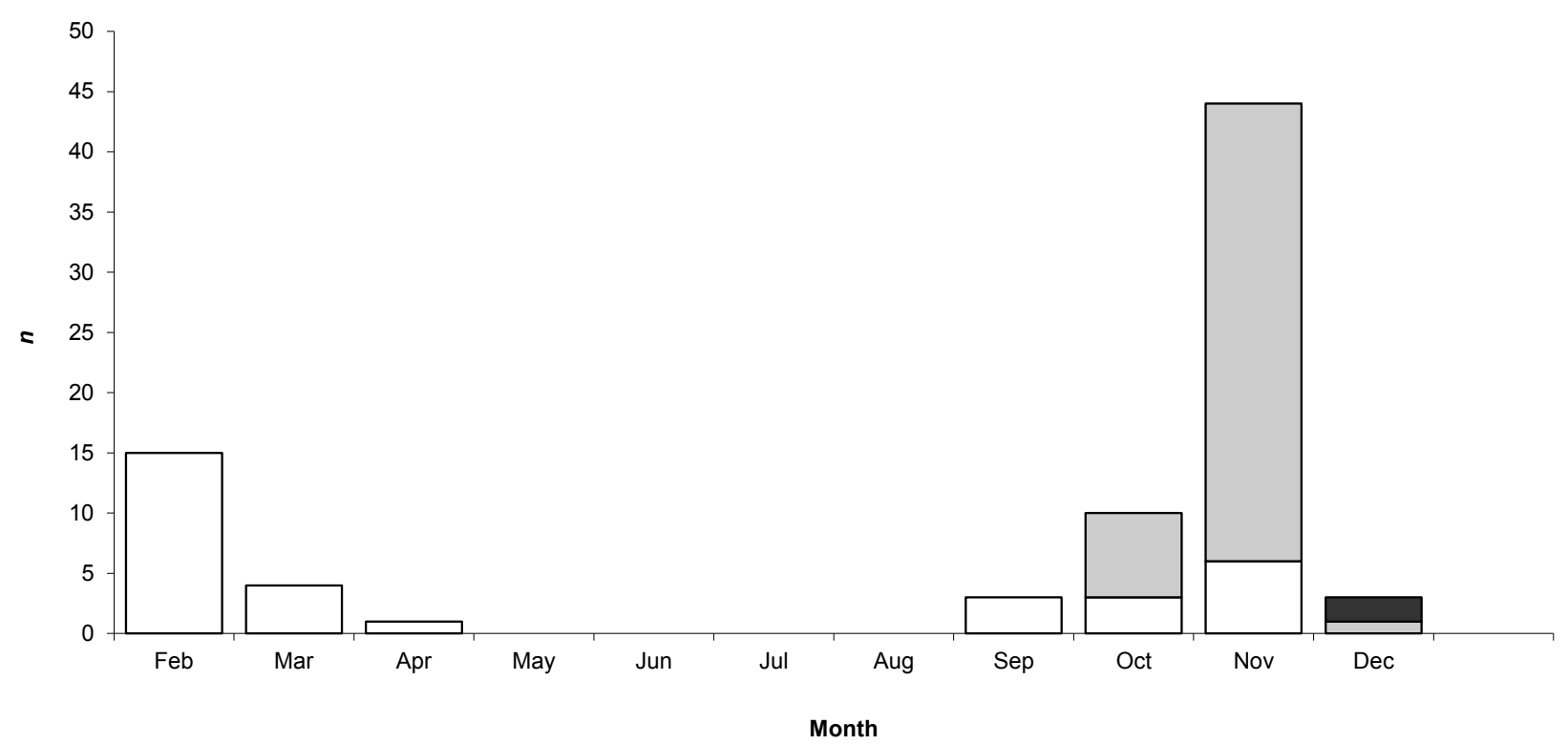

Figure 3. Reproductive activity for Euastacus sulcatus females above the minimum size at egg bearing (OCL $51.5 \mathrm{~mm})$, by month of capture: without eggs or juveniles (white); carrying eggs (grey); and (iii) carrying juveniles (black).

\section{Egg and Juvenile Development}

The initial stages of egg development could not be recorded, due to the absence of adults from the water during the cooler months. Compared to observations for egg development in three other regional species (Coughran 2006a, 2011a,b), it was estimated that eggs were one to two weeks old when the females reappeared in spring.

Throughout the broad distribution surveys, undeveloped eggs (lacking any internal development) were only observed on a few specimens collected at Grady's Creek, in the Border Ranges NP, in 2003. At this site, adults were found carrying eggs at varying developmental stages (even on the same individual), and it was estimated that the eggs had been laid within the past week or two. On the same day, Brindle Creek was sampled and adults had also returned to the water, but as in other years, females were found to be carrying eggs that were more advanced in development than those on the females at Grady's Creek; moreover, egg development at Brindle Creek was more even between different females (and estimated at more than two weeks old).

The eggs of $E$. sulcatus were ovoid in shape and, prior to the yolk darkening, were opaque and pale orange-tan in colour. The yolk changed to a translucent red-brown, pink-red or orange-red colour as the yolk developed. A detailed sequence of egg development was observed that was consistent with observations for other regional species, and has been described and illustrated elsewhere (Coughran 2006a).

Eggs began hatching 35 days after capture, indicating a total gestation time of approximately 42-49 days (assuming the eggs were between 7-14 days old at the time of capture). The hatchling crayfish remained connected to the egg case by a telson thread, and the egg cases remained cemented to the pleopodal setae of the mother; these two connections provided a means of anchoring the hatchlings to the mother, in a clutch carried beneath her abdomen. At least two moults were evident while juveniles remained within the clutch, and independence from the mother was observed approximately 2.5 weeks after hatching.

Juveniles were characterized by distinctive cream bands across the first and last abdominal segments. Many independent juvenile Euastacus sulcatus from red colour form populations (Brindle Creek) developed into the blue colour form while in captivity, perhaps due to a plant-based diet (supplemental algae pellets). All of the captive juveniles also developed the prominent cream shields that in the wild were generally only observed on adults. 


\section{DISCUSSION}

\section{Distribution and General Ecology}

The Clarence River valley in NSW forms the boundary between Euastacus sulcatus and E. suttoni. The systematic relationship between these two taxa is uncertain and they may fill similar niches in their respective environments. They are both large, spiny species, and their general morphological attributes are certainly more similar to each other than to other regional crayfishes. Euastacus sulcatus is widespread in montane habitats east of the Clarence River valley, while E. suttoni is similarly widespread in montane habitats to the west. Neither species was recorded from the lower, more central habitats of the river valley.

Several poorly spinose species of Euastacus were sympatric with $E$. sulcatus, including $E$. angustus, $E$. binzayedi, E. dalagarbe, E. girurmulayn, E. guruhgi, E. jagabar, E. jagara and E. maidae. All of these species belong within a different ecomorphological group of the genus (Coughran's Group 1) to E. sulcatus (Group 2) (Coughran 2008). The larger Euastacus sulcatus dominated sympatric associations, usually excluding the smaller species from the main channel or the deeper sections of streams. However, small E. sulcatus animals were also recorded in the peripheral habitats, tributaries and gullies occupied by these smaller species. Therefore, specimens of E. sulcatus and these smaller Euastacus spp. were often collected together, and occasionally from under the same rock. Conversely, Euastacus sulcatus appears to be mutually exclusive with crayfish from within its ecomorphological group (Group 2). The species occurs in close proximity to $E$. gumar and clearly overlaps with $E$. valentulus in some areas, but it did not co-occur with these species.

\section{Activity}

If temperature is a limiting factor for E. sulcatus, restricting it to higher altitudes (as has been suggested for highland species of Euastacus generally; e.g., Riek 1969; Horwitz 1990; Merrick 1993; Morgan 1997; Coughran \& Furse 2010), then the habit of the species to disappear from the observable population over the cooler months of the year is most unusual. This pattern would be expected for a species occurring near its lower, not upper, thermal threshold. Furse et al. (2006) also recorded this for Queensland populations of E. sulcatus, however the re-emergence of adults in their study (December to January) was notably later than during the present study (October).

Although reduced winter activity has been observed for many non-Australian species (Somers \& Stechey 1986; Matthews \& Reynolds 1995; Riggert et al. 1999) and for Australian genera such as Cherax (Geddes 1990), other spiny crayfish such as E. armatus and E. bispinosus have been observed to be winter active species (Geddes 1990; Honan \& Mitchell 1995a). However, Barker (1992) noted both daily and seasonal differences in catchability between three species of Euastacus, and had to modify his survey methods accordingly. Sampling in the traditional Victorian crayfishing season (winter), he readily caught $E$. armatus but had to postpone sampling for $E$. kershawi until later in the year.

Monroe (1977) and Borsboom (1998) observed a tendency for Euastacus robertsi and E. urospinosus to sit at burrow entrances at night, which is suggestive of a nocturnal nature. However, E. sulcatus was predominantly diurnal, with greater numbers observed and caught during the day. Diurnal activity has also been recorded for Queensland populations, and is discussed further elsewhere (Coughran 2006a; Furse et al. 2006).

The tendency of Euastacus sulcatus to leave the water and walk about on land has also been reported for this and other Euastacus species (Flecker \& Flecker 1936; Clark 1937; Riek 1959; Morey \& Hollis 1997; Morey 1998; Furse et al. 2004). One reason for this would appear to be food acquisition; in several cases, $E$. sulcatus individuals were foraging on (or in) the riparian mosses and macrophytes near the water's edge. In other cases, crayfish were found some distance from the water (up to around $100 \mathrm{~m}$ ), on leaf litter on the forest floor. On one occasion, a colleague observed a large $E$. sulcatus on the forest floor feeding on a deceased sugar glider (David Newell, Southern Cross University, pers. comm. 2004).

Many crayfish were recaptured from the immediate area in which they had been previously released, as much as 21 months earlier, suggesting that despite their propensity for substantial overland and in-stream movement, they show high burrow fidelity, with a well-established and permanent burrow to which they continue to return. Long term studies on other Euastacus species have reported similar findings: Honan \& Mitchell (1995a) found most E. bispinosus moved $<75$ $\mathrm{m}$ during their study, and Morey (1998) recaptured $E$. kershawi animals in the same vicinity up to four years after release.

\section{Moulting, Growth and Longevity}

The apparently decreasing moult increment with increasing size is commonly reported for crustaceans (Hartnoll 1983), but is not consistent with E. sulcatus 
laboratory growth studies by Furse \& Wild (2004), who found moult increment increased with increasing crayfish size. These contrasting findings might be due to differences between the source populations, or more likely the effects of the laboratory conditions on captive animals in their study. In other species, moult increments and/or growth generally for laboratory animals have been found to be higher (e.g., Jones 1981), similar (e.g., Turvey \& Merrick 1997b) or lower (e.g., Tulonen et al. 1995) than for wild animals.

The mark-recapture work suggests that Euastacus sulcatus animals $>45 \mathrm{~mm}$ OCL only moult annually, and potentially less often in substantially larger animals. A number of individuals caught several times during the study, including an $81.5 \mathrm{~mm} \mathrm{OCL}$ male recaptured nine times across 21 months, supported these findings. All six animals that were recaptured after periods of 12 months or more (ranging up to 21 months) appeared to have moulted only once. There were further indications of infrequent moulting in the apparently non-growing specimens that were recaptured, with intervening periods of up to eight months without moult, and a low incidence of recently moulted animals captured throughout the study. Furse \& Wild (2004) also recorded long intermoult periods for E. sulcatus (i.e., up to 821 days).

The potentially longer than annual moulting interval for large $E$. sulcatus is similar to findings for the large spiny crayfish $E$. bispinosus and E. kershawi, for which no moulting, or moults with an insignificant increment, have been recorded (Honan \& Mitchell 1995b; Morey 1998). Some of the moult increments recorded in the present study were so small that they could essentially be considered as negligible (and for such small increments the measuring error also limits accuracy). It may be the case that for large animals, moulting is undertaken to produce a clean exoskeleton, and/or to rehabilitate limbs or wounds, rather than necessarily increasing in size. The high incidence of wounds in this species suggests that aggressive interactions are common; repairing this physical damage and regenerating limbs would require considerable redirection of energy resources that would otherwise be available for growth. The high proportion of clean exoskeleton states also suggests that, in general, females moult prior to spawning.

A wide range of age estimates have been reported for other large Euastacus (e.g., 22-39 years for 110-120 mm OCL E. spinifer; Turvey \& Merrick 1997c), and the moult increment variation in the present study similarly presents difficulty for $E$. sulcatus age estimation. The paucity of juvenile growth data also makes the approximation of age for these species difficult. Juveniles that survived in aquaria grew at varying rates, although noticeably slower ( $15-20 \mathrm{~mm} \mathrm{OCL}$ in 18 months) than two congeners that were studied concurrently, E. gumar and $E$. valentulus. It is likely that juveniles in the wild also exhibit different growth rates.

Based on the growth rates observed in captivity, it would be a reasonable assumption that wild animals at around $25 \mathrm{~mm}$ OCL could be anywhere from 2-4 years old. Studies on other Euastacus have also indicated that at least two to three years would be required to attain 25mm OCL (Turvey \& Merrick 1997c; Borsboom 1998; Furse \& Wild 2004). If this is so, then based on the observed moult increments of typically $2-4 \mathrm{~mm}$ in this study, it is likely that $E$. sulcatus animals at $50 \mathrm{~mm}$ OCL (the size at female maturity) could be at least 8-10 years old. Animals at $70 \mathrm{~mm}$ OCL could easily be over 20 years old.

The lower moult increments observed in animals above this size (approximately $1-2 \mathrm{~mm}$ ) suggest that growth from 70-90 mm OCL could take a further 10-20 years. This slow development was also clearly expressed in the AbGRs for four animals $>70 \mathrm{~mm} \mathrm{OCL}$, over periods of more than 12 months. At a growth rate of $0.1-0.2$ $\mathrm{mm}$ per month, an increase in OCL from 70-99 mm could be expected to take 12 to 24 years. At $99.1 \mathrm{~mm}$ $\mathrm{OCL}$, the largest animal recorded could have conceivably been in the vicinity of 40 to 50 years old.

Like those recorded for E. gumar (Coughran 2011a), these AbGRs are extremely low, and suggest that these animals would require around three years to increase $<15 \mathrm{~mm}$ in OCL (and for larger animals, $<10 \mathrm{~mm}$ ). These AbGRs are also much lower than those recorded for Cherax destructor by Lake \& Sokol (1986); although there are fewer data in the present study, the time spans between captures are much longer than those available for Lake \& Sokol's (1986) study, and reflect growth over annual time scales. If non-moulting animals had been included in the analysis, the AbGRs for this species would have been far lower than those presented.

While these long term growth records clearly indicate greater longevity than Furse et al. (2004) predicted for Queensland animals (i.e., 17 years), further research is needed to obtain more precise growth and longevity estimates. Similar to other crustaceans (Hartnoll 1983), the combination of infrequent moult intervals with exceptionally small moult increments substantially limited the effectiveness of indirect age and growth estimation methods for this species. Therefore, for slow-growing and long-lived species like E. sulcatus, direct ageing methods would be ideal and could 
potentially resolve the uncertainties mentioned here; recent advances in ageing studies have demonstrated widespread potential applicability (Leland et al. 2011; Kilada et al. 2012).

\section{Reproduction}

Euastacus sulcatus is a large species with a comparatively moderate fecundity, carrying fewer eggs (45-600) than the maxima recorded for other large spiny crayfishes, such as E. armatus (800), E. bispinosus (812), E. kershawi (>1000), E. spinifer (1299) and E. valentulus $(>1000)$, but more eggs than much smaller congeners such as E. australasiensis (155), E. girurmulayn (50), E. gumar (150), E. hirsutus (84), E. mirangudjin (80) and E. urospinosus (119) (Clark 1937; Barker 1992; Honan \& Mitchell 1995c; Morgan 1997; Borsboom 1998; Honan 1998; Morey 1998; Coughran 2006a, 2011a,b). Although Morgan (1988) and Furse et al. (2006) noted that the species carried eggs over winter, it appears that the breeding season in the present study was more protracted. Mature females emerging in mid-spring were captured with relatively undeveloped eggs, and given the relatively quick development period observed for eggs and juveniles (two months) it is likely that the breeding cycle was completed in its entirety from spring to early summer.

It is possible that females over-winter eggs that enter a diapause stage (i.e., a period during which growth and development are suspended), as has been noted for the New Zealand species Paranephrops zealandicus (Whitmore \& Huryn 1999). However, based on the timing of egg development in the present study, and observed concurrently on congeners (Coughran 2006a), it seems more likely that $E$. sulcatus lays, or at least fertilizes, the eggs in spring. The inconsistency with the observations of Morgan (1988) and Furse et al. (2006) might be due to the effects of environment or location (Turvey \& Merrick 1997a), or erratic spawning out of season (Clark 1937; Hopkins 1967) in either the Queensland or NSW studies. It is also possible that the species produces two broods each year, however if this were the case two cohorts of independent juveniles should have been observed in the field surveys.

\section{Implications for Conservation}

The very slow growth rate and apparent longevity of Euastacus sulcatus renders it highly vulnerable to over-fishing, and the mass spawning pattern also leaves these populations susceptible to cohort-wide impacts, particularly given the high catchability of berried females when they re-emerge during late spring. Given their conspicuous presence, ease of capture (they can simply be collected by hand while walking the stream) and popularity (i.e., to fishers and collectors), longterm population impacts are possible, even under light fishing pressure. Based on the above, the species can be considered as an unsustainable resource.

Although E. sulcatus is protected in Queensland (Fisheries Queensland 2012), generic fishing regulations (i.e., those covering all spiny crayfish generally) in NSW allow recreational fishers to take five crayfish $>90 \mathrm{~mm} \mathrm{OCL}$ per day (NSW Department of Primary Industries 2012). The regulations thus provide protection for mature animals between 50 and $90 \mathrm{~mm} \mathrm{OCL}$, and in that sense are sufficient for the species as a whole. Furthermore, most of the populations should be protected by their distribution within national park boundaries. However, illegal fishing activities appear to be common (author, pers. obs.; Coughran \& Furse 2010). It is therefore recommended that NSW fishing regulations are revised to address more specific conditions. For E. sulcatus, the pertinent points are that berried females (which this study has demonstrated are highly catchable) should be returned to the water, and that national parks and conservation reserves are no-take exclusion zones. Increased educational materials (e.g., signage and brochures) within national parks, particularly at key camping and visitation areas, could also help mitigate poaching.

Although the species appears to be morphologically similar throughout its range, there were biological differences recorded for the NSW populations of $E$. sulcatus in this study compared to previous work on the species: (i) the timing of re-emergence of adults was two months earlier than has been recorded in Queensland; (ii) the reproductive period was more protracted, extending from spring to early summer, rather than winter to summer as has been recorded in Queensland; (iii) the moulting records suggest a much slower growth rate and increased longevity than has been previously recognised; and (iv) distinct colour variants have been recorded for different highland populations.

In light of these differences, and the restriction of the species to distinct highland areas throughout its range, it is recommended that molecular analyses be used to assess potential genetic distinctions between populations. If there is any cryptic variation within the taxon, it is important that this is recognised to facilitate conservation. It is also recommended that further research is invested into direct ageing methods for $E$. sulcatus, and other, slow growing and long-lived spiny crayfish. 


\section{REFERENCES}

Barker, J. (1992). The Spiny Freshwater Crayfish Monitoring Program. Fisheries Management Report No. 44. Inland Fisheries Management Branch, Fisheries Management Division, Department of Conservation and Environment, Victoria, 31pp.

Borsboom, A. (1998). Aspects of the biology and ecology of the Australian freshwater crayfish, Euastacus urospinosus (Decapoda: Parastacidae). Proceedings of the Linnean Society of New South Wales 119: 87-100.

Chapman, D.G. (1952). Inverse, multiple and sequential sample censuses. Biometrics 1952(December): 286-306.

Clark, E. (1937). The life history of the Gippsland crayfish. Australian Museum Magazine June 1937: 186-192.

Coughran, J. (2000). The distribution, habitat and conservation status of Euastacus gumar (Decapoda: Parastacidae), in northeastern New South Wales. Honours Thesis, School of Resource Science and Management, Southern Cross University, Australia, 74pp.

Coughran, J. (2006a). Biology of the Freshwater Crayfishes of Northeastern New South Wales, Australia. PhD Thesis, Southern Cross University, Lismore, New South Wales, Australia, 330pp.

Coughran, J. (2006b). Field Guide to the Freshwater Crayfishes of Northeastern New South Wales. Natureview Publishing, Bangalow, NSW, (CD-ROM).

Coughran, J. (2008). Distinct Groups in the genus Euastacus? Freshwater Crayfish 16: 123-130.

Coughran, J. (2011a). Biology of the Blood Crayfish, Euastacus gumar Morgan, 1997, a small freshwater crayfish from the Richmond Range, northeastern New South Wales. Australian Zoologist 35(3): 685-697.

Coughran, J. (2011b). Biology of the Orange-bellied Crayfish, Euastacus mirangudjin Coughran, 2002. Australian Zoologist 35(3): 750-756.

Coughran, J. \& J.M. Furse (2010). An assessment of genus Euastacus (49 species) versus IUCN Red List criteria. Report prepared for the global species conservation assessment of crayfishes for the IUCN Red List of Threatened Species. The Environmental Futures Centre, Griffith School of Environment, Griffith University, Gold Coast Campus, Queensland, Australia, 170pp.

Fisheries Queensland (2012). Size and Bag Limits: Freshwater. Department of Agriculture, Fisheries and Forestry, Queensland. $<$ www.daff.qld.gov.au>. Online version dated 01 June 2013.

Flecker, H. \& P.O. Flecker (1936). The haunt of the north Queensland spiny crayfish. North Queensland Naturalist IV(41): 18-20.

Furse, J.M., C.H. Wild, S. Sirotti \& H. Pethybridge (2006). The Daily Activity Patterns of Euastacus sulcatus (Decapoda: Parastacidae) in Southeast Queensland. Freshwater Crayfish 15: 139-47.

Furse, J. \& J. Coughran (2010). Euastacus sulcatus. In: IUCN 2012. IUCN Red List of Threatened Species. Version 2012.2. <www.iucnredlist. org>. Online version dated 26 May 2013.

Furse, J.M. \& C.H. Wild (2002a). Prediction of crayfish density from environmental factors for Euastacus sulcatus (Crustacea: Decapoda: Parastacidae). Freshwater Crayfish 13: 316-329.

Furse, J.M. \& C.H. Wild (2002b). Terrestrial activities of Euastacus sulcatus, the Lamington Spiny Crayfish (Short Communication). Freshwater Crayfish 13: 604.

Furse, J.M. \& C.H. Wild (2004). Laboratory moult increment, frequency, and growth in Euastacus sulcatus, the Lamington Spiny Crayfish. Freshwater Crayfish 14: 205-211.

Furse, J.M., C.H. Wild \& N.N. Villamar (2004). In-stream and terrestria movements of Euastacus sulcatus in the Gold Coast hinterland: developing and testing a method of accessing freshwater crayfish movements. Freshwater Crayfish 14: 213-220.

Geddes, M. (1990). Crayfish, pp. 302-307. In: Murray Darling Basin Commission (ed.). The Murray. Imprint Limited, Brisbane, 382pp.

Hamr, P. \& A. Richardson (1994). Life history of Parastacoides tasmanicus tasmanicus Clark, a burrowing freshwater crayfish from south-western Tasmania. Australian Journal of Marine and Freshwater Research 45(4): 455-70; http://dx.doi.org/10.1071/ MF9940455
Hamr, P. (1997). A giant's tale: the life history of Astacopsis gouldi (Decapoda: Parastacidae) a freshwater crayfish from Tasmania. Freshwater Crayfish 11: 13-33.

Hartnoll, R.G. (1983). Strategies of Crustacean growth. Australian Museum Memoirs 18: 121-131.

Honan, J.A. (1998). Egg and juvenile development of the Australian freshwater crayfish, Euastacus bispinosus Clark (Decapoda: Parastacidae). Proceedings of the Linnean Society of New South Wales 119: 37-54.

Honan, J.A. \& B.D. Mitchell (1995a). Catch characteristics of the large freshwater crayfish Euastacus bispinosus Clark (Decapoda: Parastacidae), and implications for management. Freshwater Crayfish 10: 57-69.

Honan, J.A. \& B.D. Mitchell (1995b). Growth of the large freshwater crayfish Euastacus bispinosus Clark (Decapoda: Parastacidae). Freshwater Crayfish 10: 118-131.

Honan, J.A. \& B.D. Mitchell (1995c). Reproduction of Euastacus bispinosus Clark (Decapoda: Parastacidae), and trends in the reproductive characteristics of freshwater crayfish. Marine and Freshwater Research 46: 485-99.

Hopkins, C.L. (1967). Breeding in the freshwater crayfish Paranephrops planifrons White. New Zealand Journal of Marine and Freshwater Research 1: 51-58.

Horwitz, P. (1990). The conservation status of Australian freshwater crustacea. Australian National Parks and Wildlife Service Report Series, No. 14, 121pp.

Jones, J.B. (1981). Growth of two species of freshwater crayfish (Paranephrops spp.) in New Zealand. New Zealand Journal of Marine and Freshwater Research 15(1): 15-20.

Kilada, R., B. Sainte-Marie, R. Rochette, N. Davis, C. Vanier \& S. Campana (2012). Direct determination of age in shrimps, crabs, and lobsters. Canadian Journal of Fisheries and Aquatic Sciences 69: 1728-1733; http://dx.doi.org/10.1139/cjfas-2012-0254

Lake, P.S. \& A. Sokol (1986). Ecology of the yabby Cherax destructor Clark (Crustacea: Decapoda: Parastacidae) and its potential as a sentinel animal for mercury and lead pollution. Australian Water Resources Council Technical Paper No. 87. Australian Government Publishing Service, Canberra, 186pp.

Leckie, S.R. (1999). The habitat preferences of Australian freshwater fish and crustacean species in Iron Pot Creek, Toonumbar National Park. Integrated Project, Southern Cross University, Australia, 46pp.

Leland, J., J. Coughran \& D. Bucher (2011). A preliminary investigation into the potential value of gastric mills for ageing crustaceans. Crustaceana Monographs 15 (Special Edition: New Frontiers in Crustacean Research): 57-68.

Matthews, M.A. \& J.D. Reynolds (1995). A population study of the White-clawed Crayfish Austropotamobius pallipes (Lereboullet) in an Irish reservoir. Biology and Environment: Proceedings of the Royal Irish Academy 95B(2): 99-109.

Merrick, J.R. (1993). Freshwater Crayfishes of New South Wales. Linnean Society of New South Wales, Sydney, 127pp.

Monroe, R. (1977). A new species of Euastacus (Decapoda: Parastacidae) from north Queensland. Memoirs of the Queensland Museum 18(1): 65-7, plate19.

Morey, J. \& G. Hollis (1997). Australia's most diverse crayfish habitat? Memoirs of the Museum of Victoria 56(2): 667-669.

Morey, J.L. (1998). Growth, catch rates and notes on the biology of the Gippsland spiny freshwater crayfish, Euastacus kershawi (Decapoda: Parastacidae), in west Gippsland, Victoria. Proceedings of the Linnean Society of New South Wales 119: 55-69.

Morgan, G.J. (1988). Freshwater Crayfish of the Genus Euastacus Clark (Decapoda: Parastacidae) From Queensland. Memoirs of the Museum of Victoria 49 (1): 1-49.

Morgan, G.J. (1991). The spiny freshwater crayfish of Queensland. Queensland Naturalist 31 (1-2): 29-36.

Morgan, G.J. (1997). Freshwater crayfish of the genus Euastacus Clark (Decapoda: Parastacidae) from New South Wales, with a key to all species of the genus. Records of the Australian Museum (1997) Supplement 23, 110pp; http://dx.doi.org/10.3853/j.0812- 
7387.23.1997.429\#sthash.gB3VFZac.dpuf

NSW National Parks and Wildlife Service (2001). Hygiene Protocol for the Control of Disease in Frogs. Information Circular No. 6. NSW National Parks and Wildlife Service, Hurstville, NSW, $15 \mathrm{pp}$.

NSW Department of Primary Industries. (2012). New South Wales Recreational Fishing Guide 2013. New South Wales Government. <www.dpi.nsw.gov.au>. Online version dated 25 May 2013.

Ricker, W.E. (1975). Computation and Interpretation of Biological Statistics of Fish Populations. Department of the Environment Fisheries and Marine Service, Ottawa, 382pp.

Riek, E.F. (1951). The freshwater crayfish (Family Parastacidae) of Queensland, with an appendix describing other Australian species. Records of the Australian Museum 22 (4): 368-388.

Riek, E.F. (1959). The Australian Freshwater Crustacea, pp. 246-258. In: Keast, A., R.L. Crocker \& C.S. Christian (eds.). Biogeography and Ecology in Australia. Uitgeverij Dr. W. Junk, Den Haag, Netherlands, 640pp.

Riek, E.F. (1969). The Australian freshwater crayfish (Crustacea: Decapoda: Parastacidae) with descriptions of new species. Australian Journal of Zoology 17(5): 855-918; http://dx.doi. org/10.1071/ZO9690855

Riggert, C.M., R.J. Distefano \& D.B. Noltie (1999). Distributions and selected aspects of the life histories and habitat associations of the crayfishes Orconectes peruncus (Creaser, 1931) and $O$. quadruncus (Creaser, 1933) in Missouri. The American Midland Naturalist 142(12): 348-362; http://dx.doi.org/10.1674/00030031(1999)142[0348:DASAOT]2.0.CO;2
Schnabel, Z.E. (1938). The estimation of the total fish population of a lake. American Mathematical Monthly 45: 348-352.

Somers, K.M. \& D.P.M Stechey (1986). Variable trappability of crayfish associated with bait type, water temperature and lunar phase. The American Midland Naturalist 116(1): 36-44.

Tulonen, J., E. Erkamo \& J. Kirjavainen (1995). Growth rate, survival and reproduction of noble crayfish (Astacus astacus (L.)) and signal crayfish (Pacifastacus leniusculus (Dana)) under similar rearing conditions. Freshwater Crayfish 10: 623-629.

Turvey, P. \& J.R. Merrick (1997a). Reproductive biology of the freshwater crayfish, Euastacus spinifer (Decapoda: Parastacidae), from the Sydney region, Australia. Proceedings of the Linneaen Society of New South Wales 118: 131-155.

Turvey, P. \& J.R. Merrick (1997b). Moult increments and frequency of the freshwater crayfish, Euastacus spinifer (Decapoda: Parastacidae), from the Sydney region, Australia. Proceedings of the Linneaen Society of New South Wales 118: 187-204.

Turvey, P. \& J.R. Merrick (1997c). Growth with age of the freshwater crayfish, Euastacus spinifer (Decapoda: Parastacidae), from the Sydney region, Australia. Proceedings of the Linneaen Society of New South Wales 118: 205-215.

Whitmore, N. \& A.D. Huryn (1999). Life history and production of Paranephrops zealandicus in a forest stream, with comments about the sustainable harvest of a freshwater crayfish. Freshwater Biology 42(3): 467-478; http://dx.doi.org/10.1046/j.13652427.1999.00482.x 